\title{
Endoscopic retrieval of baggies in body stuffers
}

Authors

Institutions
Mahtab Shabani ${ }^{1}$, Nasim Zamani ${ }^{2,3}$, Hossein Hassanian-Moghaddam²,3

${ }^{1}$ Department of Internal Medicine, Loghman-Hakim Hospital, Shahid Beheshti University of Medical Sciences, Tehran, Iran Toxicological Research Center, Department of Clinical Toxicology, Loghman-Hakim Hospital, School of Medicine, Shahid Beheshti University of Medical Sciences, Tehran, Iran

Excellence Center of Clinical Toxicology, Ministry of Health, Tehran, Iran submitted

5. December 2015 accepted after revision 8. February 2016

\section{Bibliography}

DOI http://dx.doi.org/

10.1055/s-0042-103242

Published online: 30.3.2016

Endoscopy International Open

2016; 04: E443-E445

(c) Georg Thieme Verlag KG

Stuttgart · New York

E-ISSN 2196-9736

Corresponding author

Hossein Hassanian-

Moghaddam, MD, FACMT

Department of Clinical

Toxicology

Loghman Hakim Hospital

Kamali Street

South Karegar Avenue

Tehran 1333431151

Iran

Phone: +9821-55409534

Fax: +9821-55409534

Hassanian@sbmu.ac.ir

Hasanian2000@yahoo.com
Background and study aims: Body packing/stuffing is currently a huge medical problem. A conservative approach and waiting for spontaneous packet expulsion are usually recommended. However, in a patient with packets stuck in the stomach, surgical treatments are generally advocated if complications occur.

Endoscopic evacuation of the packets is generally not favored because of its potential hazards, in-

\section{Introduction \\ $\nabla$}

Body packing/stuffing is currently a huge health care and legal problem in many countries of the world. If complications occur in a patient with a packet/baggy stuck in the stomach, surgical treatments are generally advocated, although they may be ineffective and even harmful [1].

Endoscopic extraction of the packets is generally not favored because of its potential hazards including manipulation and rupture of the packets and deterioration of the patients' condition [2]. However, in selected cases, it may prevent more invasive treatments including surgical intervention, which may be dangerous and even lethal [1, 3].

We have already shown that the best available method of diagnosis of body stuffing is computed tomography (CT) scanning without oral contrast [4]. Using different windows - particularly the lung window - may increase the sensitivity of diagnosis and facilitate rough estimation of the size of the baggies and the probable amount of the toxic material [5]. We performed CT scanning without contrast in all cases because we knew that most body stuffers were detainees who might lie to the police and medical staff to avoid legal consequences. We present case reports of four body stuffers with potentially dangerous ingestions who underwent endoscopic retrieval of their baggies and survived. cluding manipulation and rupture of the packets and deterioration of the patients' condition. However, it may prevent more invasive treatment modalities including surgical intervention. We present case reports on four symptomatic body stuffers with potentially dangerous ingestions who underwent endoscopic evacuation of their packets and survived.

For all cases, a 12.8-mm diameter Olympus GIFH170 (Olympus, Tokyo, Japan) gastroscope, a 4mm monofilament wire (Nitonol; 2.6-mm diameter and $200-\mathrm{cm}$ length), and a $70-\mathrm{mm}$ basket (ENDO-FLEX ${ }^{\circledR}$-Germany) were used to retrieve the baggies. Midazolam was used 2 to 3 minutes before the procedure (1 to $2.5 \mathrm{mg}$, intravenous [IV]) and propofol (100 to $200 \mathrm{mcg} / \mathrm{kg} / \mathrm{min}$ ) was used for maintenance of sedation during the procedure without intubation.

The baggies were directly manipulated into the retrieval bag. The scope was passed repeatedly if there were multiple baggies (once for each packet). The plastic cover of the baggies as well as the large space between the basket wire arms minimized the hazard of rupture during the procedure. Overtubes could be used in cases in which we feared that the cover might tear. There was no correlation between retrieving baggies and endoscope diameter because the baskets were out of scope during baggy removal. The risk of rupture was minimized using medications that relaxed the upper and lower esophageal sphincters. A surgical team was available during the procedure for possible intervention in case of perforation of the baggies and urgent need for gastrostomy. Our local ethics committee in Shahid Behehsti University of Medical Sciences approved the intervention. 


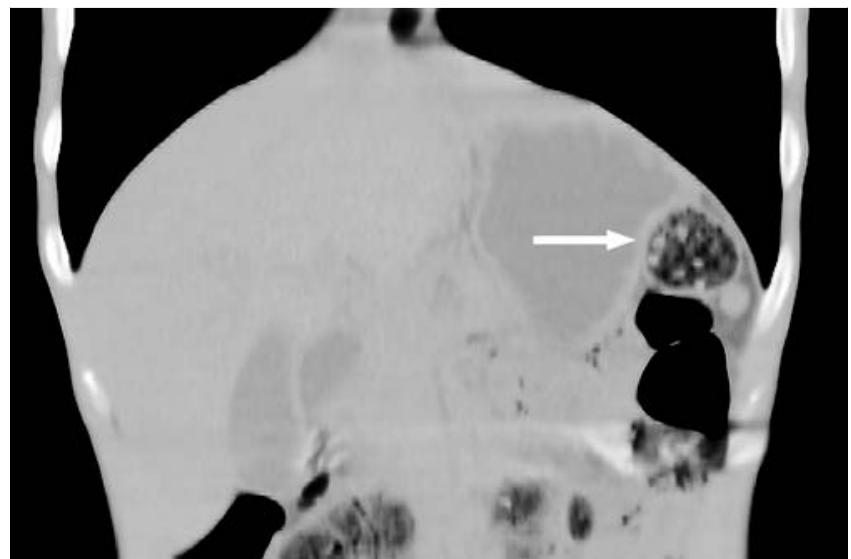

Fig. 1 Sagittal computed tomography (lung window) scan of the last patient showing a big packet that contains smaller baggies (arrow).

\section{Case Reports \\ $\nabla$}

\section{Patient 1}

A 24-year-old male was referred to us with normal vital signs and chief complaints of agitation and flushing following ingestion of one 2-g packet of methamphetamine. The patient's arterial blood gas analysis was normal. After performance of abdominopelvic CT without contrast, a hyperdense packet was detected in the stomach containing five smaller baggies. Polyethylene glycol (PEG) was given, endoscopy was performed, and the packet was safely extracted. Although the patient had attached the packet to his teeth by a string, it had been disconnected and caused intoxication. There was no new damage following endoscopy. No urine screen test was available. The patient was safely discharged 1 day after endoscopy with normal vital signs and completely symptom-free.

\section{Patient 2}

A 29-year-old male was referred who denied ingestion of any drug packet after police had arrested him. On arrival, his chief complaints were drowsiness, perspiration, agitation, and bradycardia (pulse rate 51 beats per minute). The man's pupils were dilated and reactive to light. An abdominopelvic CT revealed a single $34 \times 12$-mm hyperdense packet in the patient's stomach. The surgical team recommended surgical intervention. During endoscopy, the ruptured cellophane was retrieved from the man's stomach. His urine screening tests were positive for am- phetamine, methamphetamine, cannabinoids, morphine, and benzodiazepines. Whole bowel irrigation (WBI) with PEG was performed to help clear the drugs from the patient's gastrointestinal tract. He patient was discharged 2 days later in good clinical condition and symptom-free.

\section{Patient 3}

A 32-year-old male was referred with the history of ingestion of two packets, one containing $2 \mathrm{~g}$ of heroin and the other containing $10 \mathrm{~g}$ of methamphetamine. After four defecations, the packets had not been expelled. On arrival, the patient's pupils were dilated and he was agitated. CT revealed two overlapping packets in his stomach. On endoscopy, the packets were retrieved without further damage. No urine screening test was performed. The patient was discharged home 2 days later in good clinical condition and symptom-free.

\section{Patient 4}

A 27-year-old man was referred with a history of ingesting a large 20-g packet containing several heroin and methamphetamine baggies. His chief complaints were hiccups, generalized myalgia, and dysphagia. He was completely conscious on presentation and the referral was made because of fear that the packet would perforate. PEG was administered. CT scan revealed a packet in the patient's stomach ( $\mathbf{F i g . 1}$ ). On endoscopy, the packet was removed with no further damage ( $\bullet$ Fig.2 and $\odot$ Fig.3). It contained 16 baggies, two of which had perforated, causing the patient's intoxication. The man's urine screening test was positive for amphetamine, methamphetamine, and morphine. He was safely discharged 4 days later.

\section{Discussion}

$\nabla$

As mentioned, knowledge about treatment of body packers is growing worldwide and conservative treatment is now favored rather than more invasive therapies such as surgery, which was once known to be the only approved method of managing body packers and stuffers [4].

In general, serious complications following body stuffing are rare and there is no consensus on the best method for removing baggies that contain huge life-threatening amounts of drugs [6]. Although endoscopic removal of drug packets is highly controversial, some reports exist of success with the procedure [7-9]. The risk associated with this approach is primarily packet perforation,
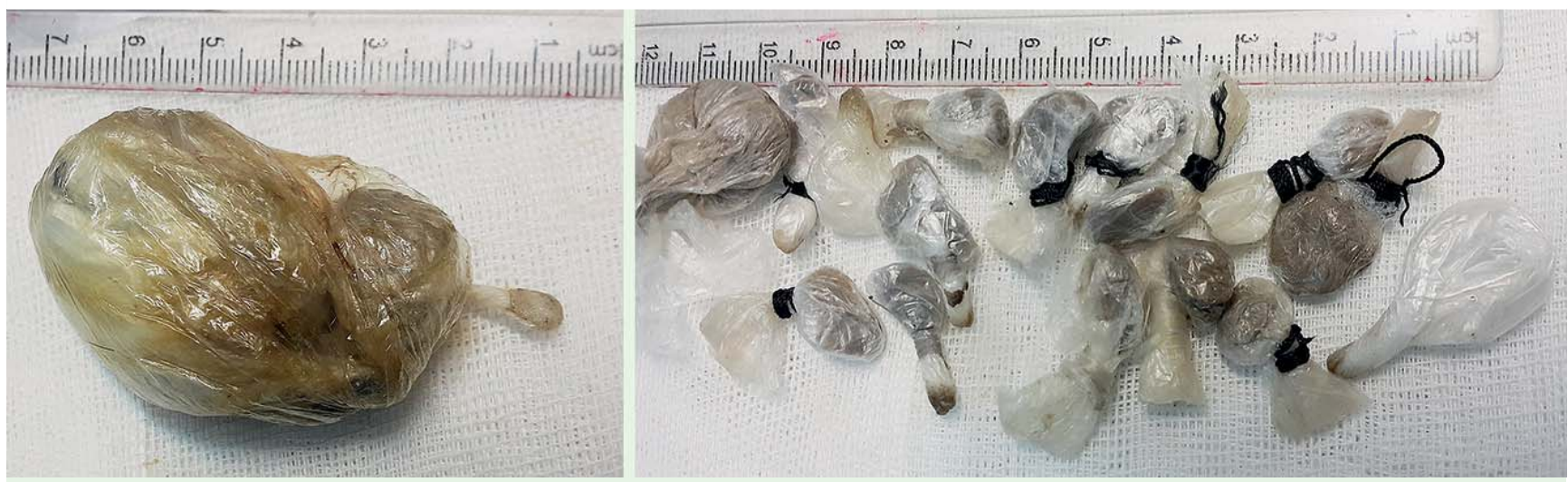

Fig. 2 The packs retrieved from the same patient after upper gastrointestinal endoscopy. Left: The main pack. Right: Baggies inside the main pack. 


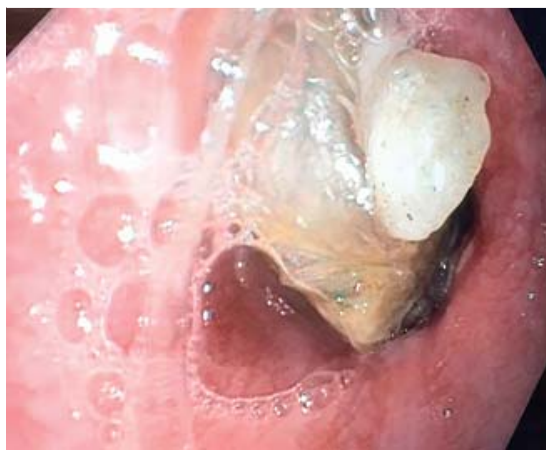

Fig. 3 View of a baggie during endoscopy

which can release dangerous amounts of drug and even cause death. Endoscopic removal typically has been attempted in body packers who have multilayer well-wrapped packets. Hoffman and Nelson believe that endoscopy may be safe when performed in a highly controlled setting, especially when a packet can be tested for strength against the snare. However, they believe that only asymptomatic patients are candidates for endoscopy when whole bowel irrigation has failed or is otherwise contraindicated [10].

Because each packet requires passage of the endoscope, endoscopy is only considered for removal of a remaining packet or a few packets that have failed to pass the pylorus [9].

All of our patients were body stuffers with loose packet wrappings who were symptomatic because of rupture of the baggies or had leakage from them. This shows that, in spite of fears about use of endoscopy for management of packers, even stuffers can be safely treated with this method. However, this may result in a problem in management of these patients. We generally prefer more conservative measures, such as administration of PEG and WBI, for initial treatment. However, use of endoscopic interventions requires early decision-making before the packet passes the pylorus. On the other hand, using the endoscope basket to manipulate baggies with loose wrappings is much more dangerous than that in body packers. Therefore, a highly controlled setting with access to an anesthesiologist and surgeon, intubation instruments, antidotes, and an operating room often is advocated. This study has some limitations that should be clarified. We performed endoscopy in four cases, which only demonstrates the feasibility but not the safety of the procedure. On the other hand, it is likely that failures or complications of endoscopic attempts to remove the packets - with severe adverse events and even death - have not been published in the past by other teams, therefore, publication bias is a matter of debate.

\section{Competing interests: None}

\section{References}

1 Bahrami-Motlagh H, Hassanian-Moghaddam H, Behnam B et al. Failure of surgical treatment in methamphetamine body-stuffers. J Forensic Leg Med 2015; 32: $70-72$

2 Beauverd Y, Poletti PA, Wolff $\mathrm{H}$ et al. A body-packer with a cocaine bag stuck in the stomach. World J Radiol 2011; 28; 3: 155-158

3 de Bakker JK, Nanayakkara PW, Geeraedts LM Jr et al. Body packers: a plea for conservative treatment. Langenbecks Arch Surg 2012; 397: $125-130$

4 Shahnazi M, Hassanian-Moghaddam H, Gachkar L et al. Comparison of Abdominal Computed Tomography with and Without Oral Contrast in Diagnosis of Body Packers and Body Stuffers. Clin Toxicol (Phila) 2015; 53: $596-603$

5 Bahrami-Motlagh $H$, Vakilian F, Pourghorban $R$ et al. Added value of lung window in detecting drug mules on non-contrast abdominal computed tomography. La Radiologia Medica 2016: DOI 10.1007/ s11547-015-0618-x (in Press)

6 Booker RJ, Smith JE, Rodger MP. Packers, pushers and stuffers-managing patients with concealed drugs in UK emergency departments: a clinical and medicolegal review. Emerg Med J 2009; 26: 316-320

7 Choudhary AM, Taubin H, Gupta T et al. Endoscopic removal of a cocaine packet from the stomach. J Clin Gastroenterol 1998; 27: 155156

8 Sherman A, Zingler BM. Successful endoscopic retrieval of a cocaine packet from the stomach. Gastrointest Endosc 1990; 36: 152 - 154

9 Macedo G, Ribeiro T. Esophageal obstruction and endoscopic removal of a cocaine packet. Am J Gastroenterol 2001; 96: 1656-1657

10 Hoffman RS, Nelson L. Internal concealment of drugs of abuse (body packing). Up To Date 18.05.2015. http://www.uptodate.com/contents/internal-concealment-of-drugs-of-abuse-body-packing\#H4448210 (Accessed Jan 26, 2016) 